\title{
NOTAS DE CLASE SOBRE PATOLOGÍA Y SU IMPORTANCIA EN LA MEDICINA: BIOPSIA, AUTOPSIA Y PALEOPATOLOGÍA
}

\section{CLASS NOTES ON PATHOLOGY AND THEIR IMPORTANCE IN THE MEDICINE: BIOPSY, AUTOPSY AND PALEOPATHOLOGY.}

\author{
KATTY LACAYO-LEPESQUEUR, M.D. Patóloga.
}

Patólogos Asociados de Sucre, Sincelejo, Colombia.

\section{Key words:}

Human pathology, importance, biopsy,

autopsy,

paleopathology.

\section{Abstract}

The present work exposes the importance of the human pathology in the medical sciences, it emphasizes on historical aspects and it describes the different analysis techniques in which it bases its work. It is a thematic summary that shows the importance of the human pathology regarding biopsy, autopsy and paleopathology, and their value in the fight against the illness and their support in the search of the human well-being.
Palabras Clave:

Patología humana, importancia, biopsia, autopsia, paleopatología.

\section{Resumen}

El presente trabajo expone la importancia de la patología humana en las ciencias médicas, enfatiza sobre aspectos históricos y describe las diferentes técnicas de análisis en las cuales fundamenta su trabajo. Es una recopilación temática que muestra la importancia de la patología humana en lo referente a biopsia, autopsia, paleopatología, su valor en la lucha contra la enfermedad y su apoyo en la búsqueda del bienestar humano, 


\section{Introducción}

El término MESH de Patología (MeSH ID: D010336) la define como una especialidad que trata lo concerniente con la naturaleza y causa de la enfermedad según lo expresado por los cambios en la estructura y función celular o tisular causada por el proceso de una enfermedad. La patología utiliza herramientas moleculares, microbiológicas, inmunológicas y morfológicas para tratar de explicar la etiología y manifestaciones clínicas, es decir: signos y síntomas que presentan los pacientes, al tiempo que propone bases racionales para el tratamiento y profilaxis. Suele considerarse como el enlace entre las ciencias básicas y las ciencias clínicas (KUMAR et al., 2010).

Por convención, la patología suele dividirse para su estudio en dos grandes ramas: la patología general, que se ocupa de las reacciones de las células y tejidos frente a estímulos anormales y defectos genéticos; y la patología sistémica, que analiza las alteraciones de órganos y tejidos especializados.

\section{Algo de historia}

De manera puntual JAVIER-ZEPEDA (2009) indica que ninguna ciencia puede desarrollarse sin tener su propia filosofía. La ciencia médica ha progresado bajo el concepto que la enfermedad es un enemigo del bienestar y de la vida. Sin embargo, la enfermedad no siempre es el resultado de una causa deletérea. La enfermedad puede resultar de un esfuerzo de nuestros sistemas fisiológicos para preservar la integridad total del organismo. En este sentido, entender la enfermedad depende de conocer o investigar las causas y los mecanismos que la condicionan. Las enfermedades son fenómenos biológicos modulados por una variedad de respuestas de nuestros sistemas homeostáticos y para comprenderlos es necesario analizar la ciencia básica de esas respuestas y sus causas.

Según FERNÁNDEZ-DÍAZ (2012), como ejemplo se puede citar que la historia de la ciencia y por lo tanto, de la medicina y de la enfermedad está llena de metáforas, o más bien de construcciones metafóricas, que han conseguido no sólo subsistir hasta nuestros días, sino incluso residir en nuestras percepciones y en nuestros conceptos actuales. Quizá el más extendido concepto sea la dualidad entre el bien y el mal, o el caos y el orden; en las culturas antiguas, el universo físico es un campo de batalla entre el bien y el mal (DAVIS, 1993)

Señala, JAVIER-ZEPEDA (2009), que históricamente, el desarrollo del conocimiento sobre la naturaleza de la enfermedad puede considerarse dividido en seis períodos cada uno identificado por un cambio fundamental sobre el concepto de su origen. No obstante, es importante resaltar que los fundamentos sobre la enfermedad y su enfoque, desde una perspectiva evolutiva del desarrollo científico muestran un cambio que avanza a un ritmo relativamente lento.

1. Prehistoria: magia y espiritismo; las enfermedades eran atribuídas a causas sobrenaturales y ocultas, se creía en la existencia de una sola enfermedad con diversas formas de presentación, es decir, la enfermedad era un sólo mal. El concepto aún perdura en aquellos que afirman que "no hay enfermedades, sólo pacientes" JAVIER-ZEPEDA (2009).

2. Doctrina humoral: La creencia de que el cuerpo humano consistía de cuatro humores: sangre, flema, bilis amarilla y bilis negra y que las enfermedades resultaban de la pérdida del balance entre ellos, emergió con los primeros registros de la historia y fue articulada en forma más precisa por los griegos (Hipócrates, Galeno), quienes la adoptaron de los egipcios e hindúes. Estas creencias dominaron el mundo occidental hasta la época del renacimiento JAVIER-ZEPEDA (2009).

3. Anatomía Patológica: El nacimiento, crecimiento y triunfo de la patología macroscópica, hilvanado desde el perfeccionamiento del conocimiento anatómico (Vesalius), hasta que en el siglo XVII se propuso el concepto que los órganos son el sitio donde ocurre la enfermedad (Morgagni). Por su preeminencia, todavía muchos siguen considerando que el patólogo sólo es el médico especialista que hace autopsias y examina los órganos JAVIER-ZEPEDA (2009).

4. Patología tisular: La emergencia del concepto de los tejidos como subdivisiones de los órganos y considerados como los verdaderos sitios donde ocurren las enfermedades fue promovido en Francia en el siglo XVIII (Bichat). Aunque en ese entonces no se usó el microscopio para establecer esta idea, puede considerarse como el punto de partida de lo que hoy conocemos como Histopatología JAVIER-ZEPEDA (2009).

5. Patología Celular. Concepto propuesto a finales del siglo XIX (Virchow) que vino a cimentar a la Patología como una ciencia, cuando el campo entero de la Medicina ya se proyectaba en esa dirección, alejándose de ser puramente un arte. En este período comienzan a desarrollarse en forma paralela otras ciencias que vendrían a contribuir al conocimiento de la enfermedad, notablemente la Inmunología, la Microbiología y la Bioquímica JAVIER-ZEPEDA (2009).

6. Patología Molecular: Que aparece en la segunda mitad del siglo XX. Ya Virchow lo había anticipado cuando escribió [que] "la última verdad en Biología no es morfológica sino molecular". El punto de partida 
de esta etapa fue el descubrimiento de la causa de la hemoglobinopatía S en 1949 (Pauling). En los últimos sesenta años la teoría molecular de la enfermedad ha sido ampliamente aceptada y actualmente la genómica y la proteómica son las vías para explicar muchos fenómenos patológicos JAVIER-ZEPEDA (2009).

JAVIER-ZEPEDA (2009) al comparar el aprendizaje de la Medicina, conceptúa que se puede comparar con un edificio sustentado por columnas que representan las ciencias básicas, entre ellas: anatomía, embriología, histología, biología celular, bioquímica, biología molecular, biofísica, fisiología, genética, nutrición, farmacología, microbiología, parasitología, inmunología y Bioestadística, sobre las cuales descansa el entendimiento de la Patología. Y de otra parte las ciencias clínicas que representan el techo del edificio. Si las bases son débiles, el techo no se sustenta o si las bases se debilitan con el tiempo, el techo se cae.

Para responder si ese conocimiento básico es necesario para entender la Patología hay que introducir los conceptos de Etiología y Patogénesis (JAVIERZEPEDA, 2009).

Etiología (Gr. aitia: causa y logos: tratado), se refiere a las causas de las enfermedades, las cuales pueden ser intrínsecas (genéticas) o extrínsecas (adquiridas), existiendo en muchos casos una interdependencia, o sea que una predisposición genética puede aunarse a un factor ambiental para ocasionar un daño. La naturaleza de las causas adquiridas es muy variada, pudiendo ser químicas, nutricionales, infecciosas, físicas, entre otras. Los fundamentos de la etiología se adquieren con el estudio de las ciencias básicas (FERNÁNDEZ-DÍAZ, 2012; http://www.wordreference. com/definicion/etiolog\%C3\%ADa).

Patogénesis (Gr. pathos: enfermedad, sufrimiento y genos: origen, inicio) se refiere a los mecanismos responsables del desarrollo de un proceso de enfermedad. El estudio de la patogénesis constituye uno de los principales dominios o ámbitos de la Patología. Aun cuando se conoce la etiología de una enfermedad, no siempre se entiende su patogénesis. De allí la gran importancia del conocimiento básico y la investigación, ya que sólo conociendo los mecanismos de la enfermedad en forma íntima, se puede llegar a plantear mejor su prevención o a encontrar formas de terapia más racionales (FERNÁNDEZ-DÍAZ, 2012; https://es.wikipedia.org/wiki/Patog\%C3\%A9nesis).

\section{Técnicas Diagnósticas en Histopatología}

En esta parte del trabajo, siguiendo lo señalado por CHUAQUI y GONZÁLEZ (http://escuela.med.puc. cl/publ/patologiageneral/ManualPatologialndice.

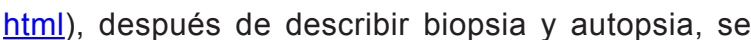
tratarán aspectos relacionados con microscopía y citodiagnóstico.

\section{La Biopsia}

Se define como el procedimiento por medio del cual se remueve tejido de un organismo vivo para examen microscópico y así establecer un diagnóstico. La muestra obtenida también se llama biopsia (http:// escuela.med.puc.cl/publ/patologiageneral/patol 121. $\underline{\mathrm{html}}$ ).

La Patología Quirúrgica es la rama de la Anatomía Patológica que se preocupa del estudio de las biopsias y difiere de la autopsia por la inmediatez del diagnóstico. El diagnóstico histopatológico muchas veces precede y determina la actitud terapéutica en un caso dado. Por consiguiente, el diagnóstico de la biopsia es siempre URGENTE. Esto es importante no sólo por la decisión terapéutica, sino que también conlleva a reducir gastos de hospitalización, ahorro de tiempo, rapidez de tratamiento, y mejorar la calidad de vida del paciente, entre otras (http://escuela.med.puc.cl/publ/ patologiageneral/patol 121.html).

Según el tipo de muestra se distinguen, según: CHUAQUI y GONZÁLEZ (http://escuela.med.puc.cl/ publ/patologiageneral/ManualPatologialndice.html).

1. Biopsia por punción: Se utiliza tanto en lesiones de tamaño pequeño como en las de mayor tamaño. Es de gran utilidad y puede tener limitaciones, sobre todo cuando el material obtenido es poco representativo de la lesión a estudiar, en dichos casos puede limitar o llevar a errores diagnósticos.

Dentro de las biopsias por punción se tienen, la biopsia por aspiración con aguja fina (fine needle aspiration biopsy, FNAB), en la cual el médico utiliza una aguja (calibre 20-25) colocada en una jeringa para extraer o aspirar una pequeña cantidad de tejido del área sospechosa. http://www.cancer.org/espanol/servicios/ comocomprendersudiagnostico/fragmentado/para-lamujer-que-afronta-una-biopsia-del-seno-biopsy-types).

También está la biopsia por punción con aguja gruesa (core needle biopsy, CNB) es similar a la FNAB. Se usa una aguja de mayor diámetro (calibre 12-14) para extraer pequeños cilindros o núcleos de tejido del área a estudiar. Con más frecuencia, la CNB se realiza en el consultorio del médico con anestesia local (la persona permanece despierta pero la región de trabajo es anestesiada. Se inserta la aguja de tres a seis veces para obtener las muestras o núcleos de tejido. Este es un procedimiento que toma más tiempo que la FNAB, pero es más probable que dé un resultado claro, ya 
que se extrae más tejido para ser examinado. La CNB puede causar equimosis, pero por lo general no deja cicatrices internas ni externas (http://www.cancer.org/ espanol/servicios/comocomprendersudiagnostico/ fragmentado/para-la-mujer-que-afronta-una-biopsiadel-seno-biopsy-types).

2. Biopsia excisional: se extirpa la lesión completa en un solo tiempo. Esta biopsia incluye habitualmente tejido normal adyacente para tener un margen de seguridad. Es ideal para lesiones pequeñas.

La biopsia excisional puede ser diagnóstica o terapéutica y se utiliza cuando se desea resecar la totalidad de la lesión ya sea benigna o maligna, dejando márgenes de seguridad para evitar la recidiva (recaída). Es de gran utilidad en el tratamiento de lesiones vasculares o pigmentadas de la piel. http://www.odontologia.unal. edu.co/docs/habilitacion/prot toma biopsias.pdf).

También se tiene la biopsia excisional guiada por arpón: se utiliza para lesiones de mama no palpables, pero mamográficamente visibles. Se realiza colocando un arpón (guía metálica) en el sitio de la anormalidad mamográfica. Después de la escisión se realiza mamografía en la biopsia y el radiólogo confirma la presencia de la lesión (LÓPEZ-CORREA y CASASBUENAS-AYALA, 2015).

Según UCHIDA et al. (2014), existe la localización con arpón bajo RM y posterior biopsia quirúrgica, lo cual coincide con los señalado por OREL y SCHNALL (2001) y por GHATE et al. (2006), que tiene la desventaja de la mayor cantidad de tejido resecado, mayor morbilidad asociada y mayores costos, pero también está la biopsia percutánea bajo RM cuyas ventajas incluyen ser un procedimiento rápido, de baja morbilidad y costos reducidos en comparación con la biopsia excisional. Este tipo de biopsia se viene realizando desde fines de los años ochenta y hay vasta experiencia publicada (GEBAUER et al., 2006).

3. Biopsia incisional: se extirpa parte de la lesión, exclusivamente con un propósito diagnóstico. Se recomienda en lesiones de gran tamaño, en las que será necesario programar ulteriormente una intervención quirúrgica de gran envergadura. La biopsia incisional se recomienda en casos de lesiones amplias, mayores de $1 \mathrm{~cm}$, en lesiones de apariencia maligna y en lesiones de difícil acceso (http://www.odontologia.unal.edu.co/ docs/habilitacion/prot toma biopsias.pdf).

Según las formas de obtención de biopsia se denominan : biopsia percutánea, es aquella en la cual el tejido se obtiene por punción a través de la piel; biopsia endoscópica, el tejido se obtiene con instrumentos (endoscopio) a través de cavidades naturales; biopsia estereotáxica, de gran utilidad en cerebro y mama, el sitio de la toma de la biopsia se hace mediante análisis externo de coordenadas; biopsia punch, la muestra se obtiene con instrumentos cilíndrico hueco llamado punch, de diámetro variable (algunos $\mathrm{mm}$ ) que permite el estudio de todas las capas de la piel e hipodermis; biopsia shave, biopsia de piel en la que la muestra se obtiene mediante corte paralelo a la superficie cutánea o afeitado (MATUTE-TURIZO y JARAMILLO, 1998; CHUAQUI y GONZÁLEZ (http://escuela.med.puc.cl/ publ/patologiageneral/ManualPatologialndice.html).

El desarrollo alcanzado por la Anatomía Patológica, gracias a la incorporación de nuevas técnicas, ha significado no sólo un aporte importante al diagnóstico médico, sino que también una exigencia cada vez mayor en cuanto a precisión y calidad del mismo.

La toma de la muestra debe considerar contar con tejido representativo, en cantidad y condiciones adecuadas. Nunca estará de más repetir que resulta imprescindible una conversación y acuerdo previos para el estudio anátomo-patológico de las muestras, no sólo con el paciente sino con el médico patólogo, sobre todo en los casos de consulta intraoperatoria o biopsia por congelación, la cual es una importante herramienta de la patología que consiste en emitir un diagnóstico histopatológico en tejido en fresco congelado y cortado en un instrumento denominado crióstato e informar resultado en el menor tiempo posible.

(CARLOSAMA-ROSERO et al., 2014).

Históricamente, según DELGADO (2007) se tiene que la primera biopsia por congelación intraoperatoria fue realizada por William Welch en 1891 para un caso sospechoso de cáncer de mama y para realizarla empleó un micrótomo de congelación de dióxido de carbono. El caso pertenecía al doctor William Halsted, jefe de cirugía del Hospital Johns Hopkins. En 1895, James Wright describió una técnica de congelación en la que se empleaba formalina. Sin embargo, el método utilizado actualmente usando un criostato fue referenciado en JAMA (Journal of the American Medical Association) por Louis Wilson de la Clínica Mayo en 1905, quien utilizó como colorante azul de metileno (WILSON, 1905 apud. CARLOSAMA-ROSERO et al., 2014).

En la actualidad el método ha sido objeto de algunas modificaciones y mejoras. Primero se requiere la obtención intraoperatoria de un fragmento de tejido. El tejido en fresco, es examinado por el patólogo quien lo describe y realiza cortes pequeños y delgados de las regiones representativas. El tejido es ubicado en una resina para congelación y es llevada al criostato. Allí es congelado a una temperatura de -35 a $-30{ }^{\circ} \mathrm{C}$ durante un tiempo aproximado de 3 a 4 minutos y en el 
interior del criostato es cortado con un micrótomo con la finalidad de obtener cortes de 4 a 6 micras de espesor (DINEHART et al., 2010; CARLOSAMA-ROSERO et al., 2014). Los cortes obtenidos se capturan en una lámina cubreobjetos y posteriormente se colorean. El colorante puede ser azul de metileno, azul de toluideno o la tradicional coloración de hematoxilina eosina. Al final del procedimiento, el patólogo emite un diagnóstico que se le remite al cirujano en pocos minutos después de haber realizado la extracción del tejido y que le permite realizar modificaciones terapéuticas intraoperatorias. A partir de 1927 y gracias al esfuerzo del doctor Joseph Bloodgood, las biopsias por congelación ganaron mayor aceptación en la práctica clínica de cirujanos y patólogos (CARLOSAMA-ROSERO et al., 2014).

Los tipos de biopsias que se señalan a continuación se fundamentan en lo planteado por LÓPEZ-CORREA y CASASBUENAS-AYALA (2015):

Biopsia colposcópica: es la biopsia en la que se obtiene tejido del cuello del útero y que realizan los ginecólogos ante una prueba de Papanicolaou positiva. Con esta biopsia se hace resección de toda la zona de transformación y del canal endocervical para evaluar lesiones premalignas y malignas del cuello uterino. Así como de otros estados patológicos del cuello uterino. (MALAREWICZ y ZYMKIEWICZ, 2008)

Biopsia de masa de partes blandas: se basa en el hecho de que una determinada lesión pueda ser o no maligna. La biopsia se realiza antes de la cirugía definitiva, ya que en determinados casos se puede indicar terapia adyuvante preoperatoria.

Biopsia de médula ósea: es la que practican los hematólogos. Obtienen muestra (cilindro de hueso y extendidos de material de médula ósea) de la cresta ilíaca pósterosuperior de la pelvis, del hueso sacro o del esternón, para determinar el origen de determinado trastornos hematológicos, principalmente.

Biopsia de perforación: es la biopsia que se realiza con una cuchilla cilíndrica hueca, que obtiene un cilindro de dos a cuatro milímetros, bajo anestesia local y con un punto de sutura. Es realizada por especialista y en el medio hospitalario.

Biopsia de tejido bronquial o transbronquial: Se realiza en el curso de una fibrobroncospia, realizada por el neumólogo.

Biopsia endomiocardica: del lado derecho u ocasionalmente del lado izquierdo. Se toman por catéter y son realizadas para evaluar rechazos en trasplante cardiaco y menos comúnmente para evaluar cardiomiopatías. De manera poco frecuente se pueden efectuar para diagnóstico de tumores intracavitarios o intramiocardicos. Es realizada por el especialista y en el medio hospitalario.

Biopsia endoscópica: es la biopsia obtenida por medio de un endoscopio que se inserta por un orificio natural o por una pequeña incisión quirúrgica. Es realizada por endoscopista. La biopsia obtenida en una colonoscopia suele ser el método más utilizado para el diagnóstico cáncer colorrectal. La biopsia de una esofagoscopia o gastroscopia puede diagnosticar la presencia de Helicobacter pilory o lesiones cancerosas de esófago o de estómago.

Biopsia estereotáxica: es un conjunto de biopsias obtenidas y guiadas por pruebas de imagen que indican las coordenadas del espacio donde se encuentra la lesión. Permite conocer la estructura tridimensional del tejido extraído. En mama se usa en el estudio de anormalidades detectadas en la mamografía, como son las microcalcificaciones. Igualmente tiene utilidad en el campo de la neurocirugía en lesiones profundas que no son susceptibles de biopsia abierta o resección. Es realizada por el especialista y en el medio hospitalario.

Biopsia ósea de una lesión osteolítica: hallada por la radiología del hueso afectado o detectado por gammagrafía ósea.

Biopsia pleural: utiliza diferentes tipos de aguja, siendo la más empleada la de Vim-Silverman. Se requiere anestesia local y es un procedimiento ciego.

Tratamiento de las muestras: Teniendo en cuenta lo señalado por CHUAQUI y GONZÁLEZ (http://escuela.med.puc.cl/publ/patologiageneral/ ManualPatologialndice.html), para el análisis patológico las muestras pueden ser conservadas (fijación) en diferentes sustancias según el estudio a realizar. El fijador convencional para incluir en parafina y estudio con hematoxilina-eosina es la formalina, que preserva la arquitectura tisular, pero puede producir alteraciones en la estructura fina de la célula, lo que puede ser inconveniente para el examen ulterior por medio de otras técnicas, especialmente con microscopía electrónica. En ciertas circunstancias, cabe aún la posibilidad de recuperar las muestras incluídas en parafina, revirtiendo todo el proceso para incluir en polímeros plásticos y obtener cortes ultrafinos para microscopía electrónica, en estos casos los resultados del estudio pueden tener limitaciones. Para las técnicas inmunohistoquímicas pueden servir los cortes usuales, de material fijado en formalina neutra.

La fijación corriente de la muestra es en formalina neutra al 10\%, (http://www.seapcongresos.com/2011/ 
SEAP/19 mayo jueves/Anfiteatro/08.00/Dolores Isabel.pdf). El volumen del fijador debe ser al menos 10 veces mayor que el del tejido a estudiar. Las muestras pequeñas (menos de $2 \mathrm{~cm}$ ) son extremadamente susceptibles a la desecación y deben colocarse inmediatamente en fijador o ser enviadas al laboratorio envueltas en una gasa humedecida en suero fisiológico. Errores comunes y frecuentes son: sumergir la muestra en suero fisiológico u otros líquidos, utilizar cantidad y concentración inadecuadas de fijador, fijación de órganos completos, todo lo cual acarrea fijación deficiente con deterioro del material y mayores posibilidades de error en la interpretación o, simplemente, inutilización definitiva del tejido. Si por razones excepcionales tiene que diferirse la fijación, las muestras podrán mantenerse en refrigerador a $4^{\circ} \mathrm{C}$.

Hay muestras que por la naturaleza del examen a realizar no deben fijarse y tienen que ser enviada en fresco al laboratorio: algunas biopsias de piel y riñón, que requieren estudio de inmunofluorescencia directa, biopsias de músculo esquelético para estudio enzimohistoquímico de miopatías y muestras de neoplasias para caracterizar inmunofenotipo como linfomas (CHUAQUI y GONZÁLEZ http://escuela.med. puc.cl/publ/patologiageneral/ManualPatologialndice. $\underline{\mathrm{html}})$.

Toda muestra para examen histopatológico o citológico debe ser identificada en el frasco, sobre o bolsa con el nombre completo del paciente y el órgano de donde procede. La muestra debe acompañarse de un formulario en el que se consigne el nombre completo, edad, sexo del paciente, órgano de donde se obtuvo, diagnóstico, antecedentes clínicos y nombre del médico que solicita el estudio. (http://www. hospitalangol.cl/documentos/ACREDITACION/9.-\%20 SERVICIOS \% 20 DE \% 20 A P Y O \% 20 DIAGNOSTICO\%200\%20TERAPEUTICO/ SERVICIO\%20DE\%20ANATOMIA\%20PATOLOGICA/ APA \%201.2/NORMAS \%20PARA \%20EL \%20 PROCEDIMIENTO \%20DE \%20REGISTRO\%20 ROTULACION\%20 TRASLADO $\% 20 \mathrm{Y} \% 20$ RECEPCION \%20DE \%20BIOPSIAS.pdf).

Recomendaciones: Todo el material extirpado debe enviarse a examen y a un solo patólogo. No es raro que la muestra sea dividida en algún momento y enviada a dos patólogos distintos simultáneamente. Este proceder es desaconsejable, porque una de las partes puede no ser representativa de la lesión en cuestión, lo que dará diagnósticos diferentes que sólo inducirán a confusión en perjuicio del paciente (MATUTETURIZO y JARAMILLO, 1998; CHUAQUI y GONZÁLEZ (http://escuela.med.puc.cl/publ/patologiageneral/ ManualPatologialndice.html).
En casos excepcionales, es aconsejable la interconsulta del material de una biopsia a otro patólogo o a instituciones de reconocida y demostrada experiencia. Es recomendable en estos casos, que todas las opiniones queden por escrito y se debe exigir material apropiado y suficiente y, por supuesto, una pregunta precisa sobre cuál es la duda o problema reales en el caso en cuestión.

En lo posible, se debe guardar siempre el material sobrante, en caso de que el material no sea procesado en su totalidad, hasta que se tenga un diagnóstico. Después del examen microscópico, no rara vez, es necesario re-examinar las piezas quirúrgicas e incluso tomar nuevas muestras. Más aún, frecuentemente el médico tratante o el cirujano, visitan la sala de biopsias para tener una visión más detallada y provechosa del caso en cuestión junto al patólogo. Todo el material que llega a Anatomía Patológica y los informes escritos correspondientes tienen que ser archivados y guardados por un tiempo prudente, a lo menos 5 años según la legislación vigente, y estar a disposición de las personas interesadas, ya sea para revisión o para investigación (MATUTE-TURIZO y JARAMILLO, 1998).

\section{La autopsia}

RODRÍGUEZ-MOGUEL (1997) indica que la autopsia es un procedimiento médico que emplea la disección, con el fin de obtener información anatómica sobre la causa, naturaleza, extensión y complicaciones de la enfermedad que sufrió en vida el sujeto autopsiado (KING y MEEHAN, 1973). Existen diversos sinónimos para este procedimiento y entre éstos destaca el de estudios postmortem; si bien la palabra postmortem literalmente significa "después de la muerte", algunos autores consideran que los ejercicios postmortem son aquellos que se realizan después de cualquier acontecimiento, con el propósito de evaluación y de superación personal (THOMAS, 1977).

BOLIO-SOLIS y RODRÍGUEZ-MOGUEL (1997) conceptúan que la realización de una autopsia es un procedimiento elaborado, complejo y cuidadoso que incluye las siguientes etapas: examen físico del cadáver, evisceración de los órganos, disección y análisis macroscópico de los mismos, toma de fotografías para dejar constancia de los hallazgos más relevantes, selección de cortes para el estudio microscópico, diagnóstico histológico, y la integración de los hallazgos macro y microscópicos para constituir los diagnósticos hasta donde sea posible. Finalmente se realiza un informe para el médico solicitante, que idealmente debe incluir la correlación anatomoclínica. En este apartado únicamente se harán algunos comentarios generales acerca de la evisceración. 
Plantean HILL y ANDERSON (1991) que los objetivos mediatos de la autopsia son el de brindar apoyo a: a) La familia; b) la sociedad; c) estudiantes de medicina; d) a los clínicos y a la práctica médica y por supuesto a e) los patólogos y a la práctica de la patología (HILL y ANDERSON, 1991). La autopsia ayuda a la familia de múltiples maneras. Una de ellas es asistiéndolos en la liberación de culpas y penas por la muerte del familiar (HIRSCH, 1984), como fuente de información genética y la alerta de posibles riesgos de contagio. Auxilia a la sociedad ya que mejora las estadísticas vitales (CARTER et al. 1981; KIRCHER, 1990;) y es una fuente de órganos y tejidos para trasplante. Además identifica nuevas enfermedades ocupacionales y ambientales, detecta epidemias incipientes de enfermedades infecciosas, provee información para asistencia legal y judicial (GANTNER, 1978) y asegura la calidad de los diagnósticos clínicos y por lo tanto de la atención hospitalaria de la comunidad (HIRSCH, 1984), entre otras (HILL y ANDERSON, 1991).

Puede considerarse que la autopsia es el único método confiable que permite confirmar el acierto diagnóstico médico en 70 a $85 \%$ de los casos. Sin embargo, estudios sistemáticos muestran que un $30 \%$ de los pacientes fallecidos y que llegan a autopsia no fueron diagnosticados correctamente en vida. El porcentaje de error diagnóstico "trascendental" de estos casos, o sea de diagnóstico con implicaciones pronósticas y terapéuticas importantes, que eventualmente podrían haber modificado la evolución en forma significativa, es de 10 a $12 \%$. Ambos porcentajes se han mantenido prácticamente inalterados en las últimas décadas.

La autopsia, es irreemplazable por la información que aporta para elaborar el certificado de defunción, pues establece la mayoría de las veces la causa de muerte en el caso individual. Así, ha podido establecerse que las infecciones por gérmenes oportunistas corresponden a la primera causa inmediata de muerte en pacientes inmunodeprimidos y que en los últimos decenios esta frecuencia se ha quintuplicado (CHUAQUI y GONZÁLEZ (http://escuela.med.puc.cl/publ/patologiageneral/ ManualPatologialndice.html).

En Colombia se reglamenta la práctica de autopsias clínicas y médico-legales, así como viscerotomías y se dictan otras disposiciones en el DECRETO 786 DE 1990 del Ministerio de Salud Pública. Las autopsias médico - legales proceden obligatoriamente en los siguientes casos: a) Homicidio o sospecha de homicidio; b) Suicidio o sospecha de suicidio; c) Cuando se requiera distinguir entre homicidio y suicidio; d) Muerte accidental o sospecha de la misma; e) otras muertes en las cuales no exista claridad sobre su causa, o la autopsia sea necesaria para coadyuvar a la identificación de un cadáver cuando medie solicitud de autoridad competente. $Y$ además son competentes para la práctica de autopsias médico - legales los siguientes profesionales: médicos dependientes de medicina legal debidamente autorizados, médicos en servicio social obligatorio, médicos oficiales, otros médicos designados para realizarlas por parte de una autoridad competente y previa su posesión para tales fines.

\section{Paleopatología}

Tomando como referencia los Apuntes de historia de la medicina (http://publicacionesmedicina.uc.cl/ HistoriaMedicina/Default.html), se entiende por paleopatología el estudio de los rastros de enfermedad dejados en fósiles y momias. Incluye también el estudio de los signos relacionados con la enfermedad en objetos arqueológicos.

Si bien es cierto que a nivel paleopatológico se logran hallazgos que son fragmentarios, se puede, a través, de ellos deducir la temporalidad de la existencia de la enfermedad, es decir desde cuando viene, qué tan ligada está a la historia del hombre. También, permite deducir si las principales enfermedades del hombre han sido las mismas a lo largo de la evolución humana, es decir cuáles han sido las formas de la enfermedad. Se estipula que es probable que no siempre hayan existido las mismas afecciones patológicas (http:// publicacionesmedicina.uc.cl/HistoriaMedicina/Default. $\underline{\mathrm{html}})$

Un argumento, que refuerza la afirmación anterior sería: los hallazgos de bacterias petrificadas en formaciones geológicas de 500 millones de años atrás, similares a las cocáceas actuales; por otra parte, se cree que los virus son de aparición posterior a la de las bacterias. Por lo tanto hubo un período en que no podía haber enfermedades virales, pero sí bacterianas. Por último, parece poco probable que todos los virus patógenos hayan aparecido simultáneamente (http:// publicacionesmedicina.uc.cl/HistoriaMedicina/Default. $\underline{\mathrm{html}})$.

Las lesiones óseas son las que mejor se representan en los estudios de paleopatología. Por ejemplo, estudios en Pithecanthropus (Homo erectus) muestra una gran exostosis en uno de los fémures (CAMPILLO, 2001); Igualmente, en Koobi Fora, a $H$. erectus se le hallaron lesiones extrañas en las piernas, siendo diagnosticado con hipervitaminosis A por comer hígado crudo en exceso que como es sabido es uno de los grandes reservorios de vitamina $A$ del cuerpo del hombre y los animales (http://www.gorgas.gob.pa/museoafc/ loscriminales/evolucion/arcantropinos.html). 
En Homo neanderthalis se han descubierto signos de artritis y trauma. En el hombre del paleolítico se han encontrado lesiones de artritis, tumores, traumas, y malformaciones, entre éstas, espina bífida y luxación congénita de la cadera (CAMPILLO, 2001). Pero los documentos más ricos proceden de las momias egipcias desde hace 4.000 años. Hay estudios de no menos de 36.000 momias, que además de las lesiones ya citadas, documentan tuberculosis ósea, el mal de Pott, mastoiditis, enfermedad de Paget de los huesos, pie bot; en tejidos blandos y vísceras se han podido identificar arterioesclerosis, neumonía, pleuritis, cálculos (renales y biliares) y apendicitis, lesiones cutáneas similares a las de la viruela y bilharziasis(http://www.autoreseditores. com/book_preview/pdf/000001982.pdf?1424131580).

Sobre la tuberculosis, BUIKSTRA y WILLIAMS (1991) detallan sobre el padecimiento de esta enfermedad en el nuevo mundo. Los primeros testimonios que acreditan la presencia de tuberculosis vertebral, tanto en la cultura muisca como en el resto del territorio colombiano, los presenta RODRÍGUEZ (1987) y recientemente ETXEBERRIA et al. (2015) hacen una investigación que aporta evidencias sobre la presencia de esta enfermedad en Colombia prehispánica. MARCSIK y PALFI (1992), han reportado varios casos desde el punto de vista de la paleopatología, consideran que la tuberculosis vertebral es la más frecuente de las formas tuberculosas osteo-articulares.
Un problema interesante que se plantea en paleopatología es el concerniente a la sífilis (HUDSON, 1965; RODRÍGUEZ y RODRÍGUEZ, 1998; ALDANA, 2006. No obstante, algunas lesiones de osteítis recuerdan las luéticas, pero rastros de la lesión ósea más característica, la osteítis gomosa del cráneo no se han encontrado ni en el hombre prehistórico ni en las momias egipcias (BAKER y ARMELAGOS, 1988). Las primeras referencias de treponematosis, las describe Standen (STANDEN y ARRIAZA, 2000) en restos humanos de la cultura Nazca. La información paleopatologíca estudiada por MASEMAN (1987) antes del descubrimiento de América, hace referencia a la sífilis como enfermedad reportada en Islas Canarias, España. Los estudios de paleo-patología, plantean que la aparición de la enfermedad, se generó en África septentrional durante el paleolítico, y que fueron los recolectores-cazadores quienes la expandieron a lo largo de sus travesías de esta forma fue traída a América por la migraciones asiáticas (COCKBURN, 1961). Sigue considerándose, por lo tanto, como lo más probable que la enfermedad llegó a Europa portada por marinos de Colón (BAKER y ARMELAGOS, 1988; ALDANA, 2006), pues de haber existido en Egipto ciertamente se habría extendido con anterioridad a Europa (BAKER y ARMELAGOS, 1988).

\section{Referencias}

ALDANA, S. 2006. La treponematosis en la historia de Colombia. Rev. Inmersa. 1 (2):2-28.

APUNTES DE HISTORIA DE LA MEDICINA. Introducción. Pontificia Universidad Católica de Chile. Disponible en: http://publicacionesmedicina.uc.cl/HistoriaMedicina/Default.html.Consultado: 10-04-2015.

BAKER, B.; ARMELAGOS, G. 1988. The Origin and Antiquity of Syphilis. Current Anthropology 29: 703-737.

BOLIO-SOLIS, A.; RODRÍGUEZ-MOGUEL, L. 1997. ¿Cómo se realiza una autopsia? ¿Cuáles son sus requisitos?. Rev Biomed 8 (3):183-185.

BUIKSTRA, J.; WILLIAMS, S. 1991. Tuberculosis in the Americas. Current perspectives. In Human Paleopathology, Current Syntheses and Future Options, edited by D. Ortner and A. Aufderheide, Págs. 161-172. Smithsonian Institution Press. Washington, DC

CAMPILLO, D. 2001. Introducción a la Paleopatología. Editorial. Bellaterra Madrid. España.

CARLOSAMA-ROSERO, Y.; REYES GUTIÉRREZ, N.; ROLÓNC, M.C.; ROSERO, E.A. 2014. Biopsia por congelación: recomendaciones en la práctica clínica y dermatológica. Rev Colomb Cancerol. 18(2):88-91.

CARTER, J.R.; NASH, N.P.; CECHNER, R.L.; PLATT, R.D. 1981. Proposal for a national autopsy data bank. Am J Clin Pathol 76(Suppl):597-617. 
CHUAQUI, J.B.; GONZÁLEZ, B.J. (editores) Técnicas de diagnóstico en histopatología. Cap.6. Manual de Patología General. 2a Ed. Pontificia Universidad Católica de Chile. Disponible en: http://escuela.med.puc.cl/publ/ patologiageneral/ManualPatologialndice.html. Consultado: 10-04-2015.

COCKBURN, T.A. 1961. The origin of the treponematoses. Bulletin of the World Health Organization 24:221-228

DAVIES, P.C.W .1993. El caos, en Imágenes y metáforas de la ciencia. Lorena Preta (ed.). Alianza Editorial. Madrid, España.

DECRETO 786 DE 1990. Diario Oficial No. 39.300 Ministerio de Salud Pública. Bogotá, D. E., a 16 de abril de 1990.

DELGADO, J.A. 2007. Realidad en biopsias por congelación. Universitas Médica. 48:37-45.

DINEHART, M.S.; COLDIRON, B.M.; HIATT, K.; BREAU, R.L. 2010. Concordance of frozen and permanent sections for the diagnosis of skin lesions. Dermatologic surgery 36:1111-1115.

ETXEBERRIA, F.; ROMERO, W.M.; HERRASTI, L. 2015. Cifosis angular de la columna vertebral: identificación del mal de pott en una momia Guane prehispánica de Colombia. Chungará (Arica) 32 (1):08-26.

EVOLUCIÓN ARCANTROPINOS. Homo erectus. Disponible en: http://www.gorgas.gob.pa/museoafc/loscriminales/ evolucion/arcantropinos.html. Consultada: 12-04-2015.

FERNÁNDEZ-DÍAZ, N. 2012. La historia de la medicina y de la enfermedad: metáforas del cuerpo y de las instituciones de la edad media al siglo XIX. Thémata. Revista de Filosofía 45:109-117.

GANTNER, G.E. 1978. The autopsy and the Law. Am J Clin Pathol 69:235-238.

GEBAUER, B.; BOSTANJOGLO, M.; MOESTA, K.T.; SCHNEIDER, W.; SCHLAG, P.M.; FELIX, R. 2006. Magnetic resonance-guided biopsy of suspicious breast lesions with a handheld vacuum biopsy device. Acta Radiol 47:907-913.

GHATE, S.V.; ROSEN, E.L.; SOO, M.S.; BAKER, J.A. 2006. MRI-guided vacuum-assisted breast biopsy with a handheld portable biopsy system. AJR Am J Roentgenol 186:1733-1736.

HILL, R.B.; ANDERSON, R.E. 1991. Pathologists and the autopsy. Am J Clin Pathol 95(suppl 1):S42-S49.

HIRSCH, C.S. 1984. Talking to the family after an autopsy. Arch Pathol Lab Med 108:513-514.

HUDSON, E.H. 1965. Treponematosis in perspective. Bulletin of the world Hwalth organization 32: 735-748.

JAVIER-ZEPEDA, C.A. 2009. Ciencias básicas y patología en la formación del médico. Rev Med Hondur 77 (3):99152.

KING, L.S.; MEEHAN, M.C. 1973, A history of the autopsy. Am J Pathol 73:514-44.

KIRCHER, T. 1990. The autopsy and vital statistics. Hum Pathol 21:166-173.

KUMAR, V.; ABBAS, A.K.; FAUSTO, N.; ASTER. J.C. 2010. Patología estructural y funcional (8a edición). Robins y Cotran. Elsevier. Philadelphia, USA.

LÓPEZ-CORREA, P; CASASBUENAS-AYALA, J. 2015. La biopsia y la citología, pilares del diagnóstico médico (i parte) / Rev.medica.sanitas 18 (1): 29-38.

MALAREWICZ, A; SZYMKIEWICZ, J. 2008. Colposcopy in modern gynecology and obstetrics. Studia Medyczne 2008; 11: 7-12.

MARCSIK, A.; PALFI, G. 1992 Problèmes du diagnostic différentiel de la tuberculose des squelettes. Munibe (Antropología-Arkeologia) 8 (Suplemento):95-98. 
MASEMAN, S. 1987. Enfermedades cutáneas e infecciones venéreas. Editorial Científico técnica. La Habana, Cuba.

MATUTE-TURIZO, G.; JARAMILLO, M.L. 1998. El laboratorio de Patología. Medicina UPB 17(1):29-42.

OREL, S.G.; SCHNALL, M.D. 2001. MR imaging of the breast for detection, diagnosis, and staging of breast cancer. Radiology 220:13-30.

RODRÍGUEZ J.V.; RODRÍGUEZ C.A. 1998. Dos posibles casos de treponematosis en restos prehispánicos del Valle del Cauca. Rev. Maguaré, Universidad Nacional de Colombia, Bogotá 13:85-98.

RODRÍGUEZ, J.V. 1987 Análisis Osteométrico, Osteoscópico, Patológico y Dental de los Restos Oseos de Soacha. Instituto Colombiano de Antropología, Informe Preliminar. Bogotá., Colombia.

RODRÍGUEZ-MOGUEL, L. 1997. Introducción. La autopsia: la consulta final. Rev Biomed 8 (3): 171-174.

STANDEN, V.; ARRIAZA, B. 2000. La treponematosis en las poblaciones prehispánicas del desierto de Atacama, norte de Chile. Rev. Antropología Chilena. 32 (2):185-193.

THOMAS, C.L. 1977. Taber's cyclopedic medical dictionary. 13a. ed. FA Davis Co.

UCHIDA, S. M.; PIZZOLON, F.F.; PINOCHET, T.M.A.; DURÁN, C.M.; GALLEGUILLOS, P.C.; WENZEL, K.H.; HORVARTH, P.E.; GÁLVEZ, T. J. 2014. biopsias mamarias bajo resonancia magnética, experiencia preliminar. Revista Chilena de Radiología 20 (1):13-18.

VEGA-RAMOS, B.E. 1997. La autopsia y sus objetivos. Rev Biomed 8 (3):177-179.

WILSON, L.B. 1905. A method for the rapid preparation of fresh tissues for the microscope. JAMA 1905:45:1737. 